\title{
Reply to "Comment on 'Operational Earthquake Forecasting: Status of Knowledge and Guidelines for Implementation by Jordan et al. [2011]' by Stuart Crampin"
}

Thomas H. Jordan ${ }^{1,2}$, Yun-Tai Chen ${ }^{3}$, Paolo Gasparini ${ }^{4,5}$, Raul Madariaga ${ }^{6}$, Ian Main ${ }^{7}$, Warner Marzoceh.8 Gerassimos Papadopoulos ${ }^{9}$, Gennady Sobolev ${ }^{10}$, Koshun Yamaoka ${ }^{11}$, Jochen Zschau ${ }^{12}$

\author{
${ }^{1}$ Southern California Earthquake Center, Los Angeles, USA \\ ${ }^{2}$ University of Southern California, Department of Earth Sciences, Los Angeles, USA \\ ${ }^{3}$ Institute of Geophysics, China Earthquake Administration, Beijing, China \\ ${ }^{4}$ AMRA (Analisi e Monitoraggio del Rischio Ambientale) Scarl, Napoli, Italy \\ 5 Università di Napoli "Federico II", Dipartimento di Scienze Fisiche, Napoli, Italy \\ ${ }^{6}$ École Normale Supérieure, Département des Géosciences, Paris, France \\ ${ }^{7}$ University of Edinburgh, School of GeoSciences, Edinburgh, United Kingdom \\ ${ }^{8}$ Istituto Nazionale di Geofisica e Vulcanologia, Sezione Roma 1, Rome, Italy \\ ${ }^{9}$ Institute of Geodynamics, National Observatory of Athens, Athens, Greece \\ ${ }^{10}$ Institute of Physics of the Earth, Russian Academy of Sciences, Moscow, Russia \\ ${ }^{11}$ Research Center for Seismology, Volcanology and Disaster Mitigation, Graduate School of Environmental Studies, Nagoya University, Japan \\ ${ }^{12}$ Helmholtz-Zentrum, Deutsches GeoForschungsZentrum GFZ, Department Physik der Erde, Potsdam, Germany
}

\author{
Article history \\ Received February 13, 2012; accepted February 21, 2012. \\ Subject classification: \\ Earthquake interactions and probability; Seismic risk.
}

In his commentary on the International Commission on Earthquake Forecasting (ICEF) report [Jordan et al. 2011], Crampin [2012] claims that observable changes in shear-wave splitting can predict large earthquakes on short time scales with high reliability and skill, and he challenges a central ICEF finding - that no method has yet demonstrated such a predictive capability. In particular, Crampin asserts that "observations of seismic shear-wave splitting monitored at a three-borehole Stress-Monitoring Site (SMS) in central Italy could monitor stress-accumulation and stress-relaxation (crack-coalescence) before all damaging $(M \geq 5)$ earthquakes within $1000 \mathrm{~km}$ of the SMS [...] This means that installation of one expensive SMS (preferably two throughout the length of Italy) would stress-forecast the time, magnitude, and in some circumstances fault-break of all potentially damaging on the mainland of Italy".

Crampin's assertions are based on prediction methods he has advocated for several decades [e.g., Crampin et al. 1984; Crampin et al. 1990]. As part of the ICEF study, we reviewed the literature on these methods. Nothing contained in the present commentary compels us to alter our previous findings. The "evidence" in his Table 3 is primarily a listing of phenomena purportedly explained by his theory of anisotropic poro-elasticity. All of the references cited in support of these explanations are his own. In fact, the only references given for items E12-E19 are (at the time of this writing) unpublished and would therefore be disallowed from commentaries on published papers by most scientific journals. In any case, no entry in Table 3 can be construed as scientific evidence in favor of Crampin's claims regarding the predictive power of observed changes in shear-wave splitting.

Crampin is adamant that the observational data are completely consistent with his theory. In Table 2 , he lists the implied properties with the footnote: "All these properties have been observed in situ whenever appropriate recordings are available. There are no known exceptions".

There are no exceptions was repeated (three times) in his comments on a paper by Jordan and Jones [2010], where he was more explicit about the implied observations: "whenever appropriate shear-wave source-to-geophone recordings exist, widespread stress-accumulation has always been observed before large earthquakes" [Crampin 2011]. Jordan and Jones [2011] responded to this blanket assertion by citing negative results from a retrospective search for shear-wave splitting 
precursors by Ryall and Savage [1973] and studies by Aster et al. [1990, 1991], which contradicted the positive results of retrospective studies by Crampin et al. [1990, 1991]. Here we expand the list of retrospective investigations that have tested and rejected Crampin's claims to include Savage et al. [1990], Munson et al. [1995], Liu et al. [2004, 2005], and Peng and Ben-Zion [2005]. Evidently there are exceptions.

Particularly noteworthy are two high-resolution studies by Ben-Zion and his colleagues that used tight clusters of repeating earthquakes to constrain changes in shear-wave splitting before the M7.6 Chi-Chi earthquake [Liu et al. 2005] and the M7.1 Düzce earthquake [Peng and Ben-Zion 2005]. They detected no significant precursory changes, and they showed that most of the observed anisotropy is confined to a very shallow, mechanically passive layer in the top few kilometers of the crust, above the seismogenic zone.

To be operationally useful, a precursor-based method must be able to deliver predictions that have reliable probability gains relative to standard (seismicity-based) forecasts. As emphasized in the ICEF report, the best way to validate probability gain is through prospective blind-testing of the sort now underway in the Collaboratory for the study of Earthquake Predictability (CSEP) [Zechar et al. 2009, Gerstenberger and Rhoades 2010, Marzocchi et al. 2010, Nanjo et al. 2011]. This type of validation is the gold standard for the operational qualification of earthquake forecasting methodologies, and we encourage Crampin (as did Jordan and Jones [2011]) to develop his ideas into forecasting models suitable for CSEP testing. But so far, Crampin has provided no data on the two error rates-false alarms and failures-topredict - collected during either retrospective or prospective self-testing that would be required to assess his shear-wave splitting methodology. He claims to have predicted a magnitude 5 earthquake in Iceland [Crampin et al. 1999], but even this one success is questionable from a statistical perspective. In a retrospective analysis using the same data as Crampin et al. [1999], Seher and Main [2004] concluded that "it is not possible, based on the data, to formally reject the hypothesis that the magnitude 5 event was part of the normal background seismicity". They found that Crampin et al.'s [1999] analysis contained several fundamental flaws, the most notable of which was the application of a leastsquares method (which implicitly assumes a Gaussian error model) without properly accounting for the large estimation uncertainties implied by the considerable scatter in the time delay data.

Two conclusions can be drawn from the published research results: (1) neither retrospective nor prospective testing has demonstrated that Crampin's proposed prediction methodology yields any reliable probability gain relative to standard forecasts, and (2) there is very little evidence in favor of the physical model that he espouses, but a fair amount of seismological data opposed to it. The first conclusion is sufficient to reaffirm the ICEF finding in question, which concerns the demonstrated-not potential-performance of earthquake forecasts and predictions. The second indicates that Crampin's shear-wave splitting method is unlikely to be a "silver bullet" that has the potential to raise earthquake forecasting into a highprobability environment. From a scientific perspective, significant investments in the SMS technology advocated by Crampin would be ill-considered.

Crampin's long commentary includes discussions of issues that are completely irrelevant to the ICEF report, including an entire section on the "stress-monitoring of volcanic eruptions". We will leave it to the volcanologists to evaluate whether his claims regarding the use of shear-wave splitting in predicting eruptions have merit. But when stripped of this extraneous material, Crampin's [2012] complaints about the ICEF report are very similar to those in Crampin [2011]. Aside from his gratuitous quote of Schopenhauer, he makes no attempt in the former to address the issues raised by Jordan and Jones's [2011] reply to the latter. Even more telling is the fact that both of Crampin's commentaries on the ICEF report completely ignore the evidence against his model of earthquake predictability that Aster et al. [1991] and Liu et al. [2005] presented in response to two of his previous commentaries [Crampin et al. 1991, Crampin and Gao 2005].

We close by noting that Crampin [2012] is incorrect when he states that the ICEF "presupposes that there is no method for the short-term prediction of large earthquakes that has been demonstrated to be both reliable and skillful". Nowhere in the ICEF report was the inability to predict earthquakes presupposed; rather, our conclusions regarding the current status of earthquake prediction were based on a comprehensive, objective survey of published research, including Crampin's. The search for a silver bullet remains a heroic quest, despite its long and chequered history [Jordan 2006]. The continuation of this quest has been endorsed in ICEF Recommendation C: "A basic research program focused on the scientific understanding of earthquakes and earthquake predictability should be part of a balanced national program to develop operational forecasting" [Jordan et al. 2011, pp. 360-361]. However, without a scientific breakthrough, the practice of operational earthquake forecasting is likely to remain in a low-probability environment for some time to come.

\section{References}

Aster, R.C., P.M. Shearer and J. Berger (1990). Quantitative measurements of shear wave polarizations at the Anza Seismic Network, southern California: Implications for shear wave splitting and earthquake prediction, J. Geophys. Res., 95, 12499-12473.

Aster, R.C., P.M. Shearer and J. Berger (1991). Reply to "Com- 
ment by Crampin et al. on 'Quantitative measurements of shear wave polarizations at the Anza Seismic Network, southern California: Implications for shear wave splitting and earthquake prediction by R. C. Aster, P. Shearer, and J. Berger', by S. Crampin, D.C. Booth, R. Evans, S. Peacock and J. Fletcher", J. Geophys. Res., 96, 6415-6419.

Crampin, S., R. Evans and B.K. Atkinson (1984). Earthquake prediction: a new physical basis, Geophys. J. Int., 76, 147156.

Crampin, S., D.C. Booth, R. Evans, S. Peacock and J. Fletcher (1990). Changes in shear wave splitting at Anza near the time of the North Palm Springs earthquake, J. Geophys. Res., 95, 11197-11212.

Crampin, S., D.C. Booth, R. Evans, S. Peacock and J. Fletcher (1991). Comment on "Quantitative measurements of shear wave polarizations at the Anza Seismic Network, southern California: Implications for shear wave splitting and earthquake prediction by R.C. Aster, P. Shearer and J. Berger", J. Geophys. Res., 96, 6403-6414.

Crampin, S., T. Volti and R. Stefansson (1999). A successful stress-forecast earthquake, Geophys. J. Int., 138, F1-F5.

Crampin, S., and Y. Gao (2005). Comment on "Systematic analysis of shear-wave splitting in the aftershock zone of the 1999 Chi-Chi, Taiwan, earthquake: shallow crustal anisotropy and lack of precursory changes, by Y. Liu, T.-L. Teng, and Y. Ben-Zion", Bull. Seismol. Soc. Am., 95, 354-360; doi: 10.1785/0120040092.

Crampin, S. (2011). A second opinion on "Operational earthquake forecasting: some thoughts on why and how, by T. H. Jordan and L. Jones", Seismol. Res. Lett., 82, 227-230.

Crampin, S. (2012). Comment on the report "Operational Earthquake Forecasting" by the International Commistjordan@usc.edusion on Earthquake Forecasting for Civil Protection, Annals of Geophysics, 55 (1), 5-11.

Gerstenberger, M.C., and D.A. Rhoades (2010). New Zealand Earthquake Forecast Testing Centre, Pure Appl. Geophys., 167, 877-892.

Jordan, T. H. (2006). Earthquake predictability, brick by brick, Seismol. Res. Lett., 77, 3-6.

Jordan, T.H., and L.M. Jones (2010). Operational earthquake forecasting: some thoughts on why and how, Seismol. Soc. Am., 81, 571-574.

Jordan, T.H., and L.M. Jones (2011). Reply to "A second opinion on 'Operational earthquake forecasting: some thoughts on why and how, by T.H. Jordan and L. Jones' by S. Crampin and Y. Gao", Seismol. Soc. Am., 82, 231-232.

Jordan, T. H., Y.-T. Chen, P. Gasparini, R. Madariaga, I. Main, W. Marzocchi, G. Papadopoulos, G. Sobolev, K. Yamaoka and J. Zschau (2011). Operational Earthquake Forecasting: State of Knowledge and Guidelines for Implementation, Final Report of the International Commission on Earthquake Forecasting for Civil Protection, Annals of Geophysics, 54 (4), 315-391; doi: 10.4401/ag-5350.
Liu, Y., T.-L. Teng and Y. Ben-Zion (2004). Systematic analysis of shear-wave splitting in the aftershock zone of the 1999 Chi-Chi earthquake: shallow crustal anisotropy and lack of precursory variations, Bull. Seism. Soc. Am., 94, 2330-2347.

Liu, Y., Y. Ben-Zion and T.-L. Teng (2005). Reply to "A Comment on 'Systematic analysis of shear-wave splitting in the aftershock zone of the 1999 Chi-Chi, Taiwan, earthquake: shallow crustal anisotropy and lack of precursory changes, by Y. Liu, T.-L. Teng, and Y. Ben-Zion' by S. Crampin and Y. Gao", Bull. Seism. Soc. Am., 95, 361-366.

Marzocchi, W., D. Schorlemmer and S. Wiemer, eds. (2010). An earthquake forecast experiment in Italy, Special issue, Annals of Geophysics, 53 (3), 164 pp.

Munson, C.G., C.H. Thurber, Y. Li and P.G. Okubo (1995). Crustal shear wave anisotropy in southern Hawaii: spatial and temporal analysis, J. Geophys. Res., 100, 2036720377.

Nanjo, K.Z., H. Tsuruoka, N. Hirata and T.H. Jordan (2011). Overview of the first earthquake forecast testing experiment in Japan, Earth Planets Space, 63, 159-169; doi: 10.5047 / eps.2010.10.003.

Peng, Z., and Y. Ben-Zion (2005). Spatiotemporal variations of crustal anisotropy from similar events in aftershocks of the 1999 M7.4 Izmit and M7.1 Düzce, Turkey, earthquake sequences, Geophys. J. Int., 160, 1027-1043; doi: 10.1111/j.1365-246X.2005.02569.x.

Ryall, A., and W.U. Savage (1973). S-wave splitting: key to earthquake prediction?, Bull. Seismol. Soc. Am. 64, $1943-$ 1951.

Savage, M.K., W.A. Peppin and U.R. Vetter (1990). Shear wave anisotropy and stress direction in and near Long Valley caldera, California, 1979-1988, J. Geophys. Res., 95, 11195-11177.

Seher, T., and I.G. Main (2004). A statistical evaluation of a 'stress-forecast' earthquake, Geophys. J. Int. 157, 187-193.

Zechar, J.D., D. Schorlemmer, M. Liukis, J. Yu, F. Euchner, P.J. Maechling and T.H. Jordan (2009). The Collaboratory for the Study of Earthquake Predictability perspectives on computational earth science, Concurr. Comp.-Pract. E., 22, 1836-1847; doi:10.1002/ cpe.1519.

\footnotetext{
${ }^{\star}$ Corresponding author: Thomas H. Jordan, Southern California Earthquake Center, Los Angeles, USA; University of Southern California, Department of Earth Sciences, Los Angeles, USA; email: tjordan@usc.edu.

(C) 2012 by the Istituto Nazionale di Geofisica e Vulcanologia. All rights reserved.
} 